\title{
A STUDY ON COORDINATION OF A LARGE PROJECT IN A VIRTUAL ENTERPRISE
}

\author{
John P.T. Mo, Mingwei Zhou, Julia Anticev, Laszlo Nemes \\ CSIRO Manufacturing and Infrastructure Technology, AUSTRALIA
}

\begin{abstract}
Under the IMS (Intelligent Manufacturing Systems) program, CSIRO assisted the ANZAC Ship Alliance in Australia to establish a framework for coordinating team members working in a cross company project from different locations. The ANZAC Ship Alliance is a virtual enterprise formed by 3 major partners with the aim to provide management and implementation of capability changes in ANZAC class frigates. Our earlier study proved that significant modifications are essential in order to adapt project operations to different practices of individual companies. This paper describes the study of the actual processes within an ANZAC Ship Alliance project, the techniques used to identify the information and workflow as well as the relationships with the stakeholders. Development of a web-based system that significantly enhances the effectiveness of collaboration within the virtual enterprise is presented.
\end{abstract}

\section{INTRODUCTION}

The ANZAC Ship Alliance is a Virtual Enterprise formed as a non-legal entity by 3 major partners with the aim to implement capability upgrades in ANZAC class frigates. The ANZAC class frigate is a warship designed for the characteristics of Australian and New Zealand defence objectives. The Alliance is an initiative of the Defence Materiel Organisation to ensure capability changes are efficiently and effectively implemented so that the ships are combat ready, and "fit for purpose" at any given time (Mo, 2002).

ANZAC Ship Alliance is a true virtual enterprise aimed at supporting a real product over a long life time, typically 30 years. It is important that information is managed to ensure that people capture experience, knowledge and decisions for reference and use at different times. The design and operation of the information infrastructure supporting this life time information requirement has to be taken vigorously.

Our earlier study proved that significant modifications are essential in order to adapt project operations to different practices of individual companies. In that study, CSIRO demonstrated the methodology of organising and developing a structural analysis on the requirements of content management in the business processes of the virtual enterprise (Mo et al, 2003). The methodology is based on 
the GRAI method describing the relationships between decision and physical systems (Chen et al, 1997). GRAI method was developed by the University of Bordeaux initially for analysing production planning and control and later extended to enterprise information modelling. The approach is further supported by the PERA (Purdue Enterprise Reference Architecture) modelling process and analysis tools for identifying information flow and the systems that people need to perform their tasks and decision-making processes (Williams, 1994). The result of the study was reported to the management of the ANZAC Ship Alliance and changes in their philosophy and practice have been noted since then. It is agreed that continuation of this work will focus on examining the information system at project levels. In particular, in order to understand the actual processes that occur during an ANZAC Ship Alliance project, the study team has the objectives to:

- Investigate the information flow within an ASA Project.

- Identify essential interfaces between the ASA Management Office and the Project.

- Recommend software tools.

This paper describes the study of the actual processes in the execution of a ANZAC Ship Alliance project, the techniques used to identify the information and work flow as well as the relationships with the stakeholders. A web-based system that significantly enhances the effectiveness of collaboration within the virtual enterprise is presented.

\section{THE INVESTIGATION PROCESS}

After some initial exchanges of ideas, the ANZAC Ship Alliance agreed to use one of its major projects known as Harpoon to be the pilot study case. The Harpoon project is part of SEA 1348 Phase 3 and is a major modification to the ships of the ANZAC class. The project aims to install a Harpoon missile launch capability and will extend over a period of 5 years until all 8 ships are upgraded. The CSIRO team carried out a series of investigative activities in conjunction with the Harpoon project team. These activities took place at one of the major working sites of the project. Most of the meetings were held using teleconference facilities linking members from different states of Australia.

Within a period of 3 months, the CSIRO team participated in weekly project meetings in order to observe the project coordination processes and associated activities. Written notes were taken during the meetings. It was found that a lot of information discussed within weekly meetings was communicated through emails among members of the Harpoon project team. Hence, it was agreed that a system to capture email communication and documents among project members was necessary. The system was set up soon after the first Harpoon meeting and information was recorded into a repository for analysis. Documents of many different types were collected. They were analysed in terms of document flow, work sequences and information types.

In parallel with the information capture and recording activity, the research team developed a process model that described the document review process. There are many processes in the project but due to limited resources and scope of study, the document review process was chosen to illustrate how an analysis should be done 
and what it could bring to the project team. The document review process was validated by the project team and formally accepted as the working model. Based on the model, the research team installed an experimental web-based collaborative environment on a CSIRO server for a feasibility demonstration to project members. Due to defence project restrictions, only non-classified information was stored on the CSIRO server, which was external to the virtual enterprise. The environment was an initial attempt to mimic some parts of the project processes and in particular, the document review process, so that the Harpoon team members can have operating experience validating the model. The system was implemented using Lotus QuickPlace with software agents to support selected workflows (Kosheff, 1999).

\section{PROJECT SPECIFICS AND OBSERVATIONS}

In order to understand the development of the document flow model (to be described later in this paper), some background information about the working environment of the project is provided here.

- The Project Management Office (PMO) is located in Melbourne.

- The Harpoon project team members and key stakeholders are distributed in Perth, Adelaide, Sydney, Canberra and Melbourne (800 3,5000 km apart).

- The Project Manager reports to the ANZAC Ship Alliance - General Manager situated at the ANZAC Ship Alliance Management Office (ASAMO) in Perth.

- Perth is roughly a $31 / 2$ hour flight from Melbourne.

- The greatest time difference between project team members is 3 to 4 hours (depending on day light savings).

- There is need for information to be shared between offices including:
- Harpoon PMO and ASAMO
- Harpoon PMO and other projects
- Harpoon PMO and project team members sites

Hence, data communication of a reliable type over distance is required for the life the project. The amount of documents that was transmitted was considered to be moderate at the time of investigation. There was expectation that the data volume could increase significantly in the short term. The types of documents that were transmitted included:

- Project documents (Project Management Plan, Risk Management Plan, etc)

- Work breakdown structures, schedules, cost accounts

- Meeting minutes, action items and in the future, risk register

- Design documents (incl. documents from suppliers), review comments

- Unclassified Defence documents (standards, policies, etc)

- Unclassified Alliance documents and templates.

These documents are all Microsoft Office documents such as .doc, .xls, .ppt. Other types of documents (e.g. drawings) may be transmitted later in the project.

Due to the nature of the virtual enterprise, partnering companies have their own practices and standard procedures when dealing with one another in various business matters. It is not surprising to find that there are many different file formats used for 
scheduling and costing. Information about where to find certain documents in the virtual enterprise was scarce.

The aim of the Alliance is to achieve better than business as usual performance. However the Alliance Participants are to use their own internal quality accredited processes in their own company wherever possible. Hence, if the Alliance processes turned out to be different from the established practice, questions were raised immediately on whether it was a special rule or process for Harpoon. Due to the lack of a common process, questions such as "Is the document up-to-date?" and "Who endorses it first and who is next?" were often asked. The project team also agreed that a funneled mode of communication was to be used between the partner companies of the Harpoon project. The structure was effective but not always efficient. Understandably a significant amount of time was devoted to sorting out procedural issues.

The Harpoon project is the lead major project of the Alliance and a number of teething problems were noticed. For example, communication from the project to ASAMO was satisfactory in general, but there were areas where improvements were necessary. Although there was a review meeting monthly, the research team found the feedback loop from ASAMO to the project was not well established, especially in cases where the project team requested policy information on the project. There was a lack of clear specification and QA plan for the project workflows across Harpoon project team members, partners and ASAMO. On the other hand, project information gathering and aggregation at project level kept lagging behind, making it difficult for the project manager to provide up-dated information to ASA General Manager.

\section{THE ANALYSIS}

Analysis of the ANZAC Ship Alliance virtual enterprise was focussed on the document workflow. The PERA methodology was used for this study because it offered the most comprehensive top down approach to understand the links between various sections of the virtual enterprise. We started from the organisational model (Figure 1).

Next, we break the virtual enterprise into functional areas and expand the process "Design Document Review" into a hierarchical model. The "Design Document Review" process model contains 5 major elements linked together in a process structure as shown in Figure 2:

- Design Document Preparation

- Submit Design Document for Review

- Design Document Review

- Design Document Revision

- Design Document Endorsement

This process involves a large number of virtual enterprise entities, the Alliance, contractors as well as Harpoon project team members. The last two elements run exclusively from each other. Further expansion of the process model can be seen in Figure 3.

The expanded view of design document revision highlighted two key areas. The number of revisions accepted is unlimited and the exact role of internal and external 
entities allocated to process functions. Each individual element of the model assisted the implementation of the web-based workbench in some way. Subsequent to these findings, a prototype was developed using Lotus QuickPlace by the research team.

Initially, the system server was hosted by CSIRO to ensure the agents developed to facilitate the process model in Figure 2 are functioning correctly. Only unclassified defense documents were stored at this initial stage. After 3 months of actual use, the Harpoon project team moved the server into one of the member companies of ANZAC Ship Alliance and the restriction on documents is removed.

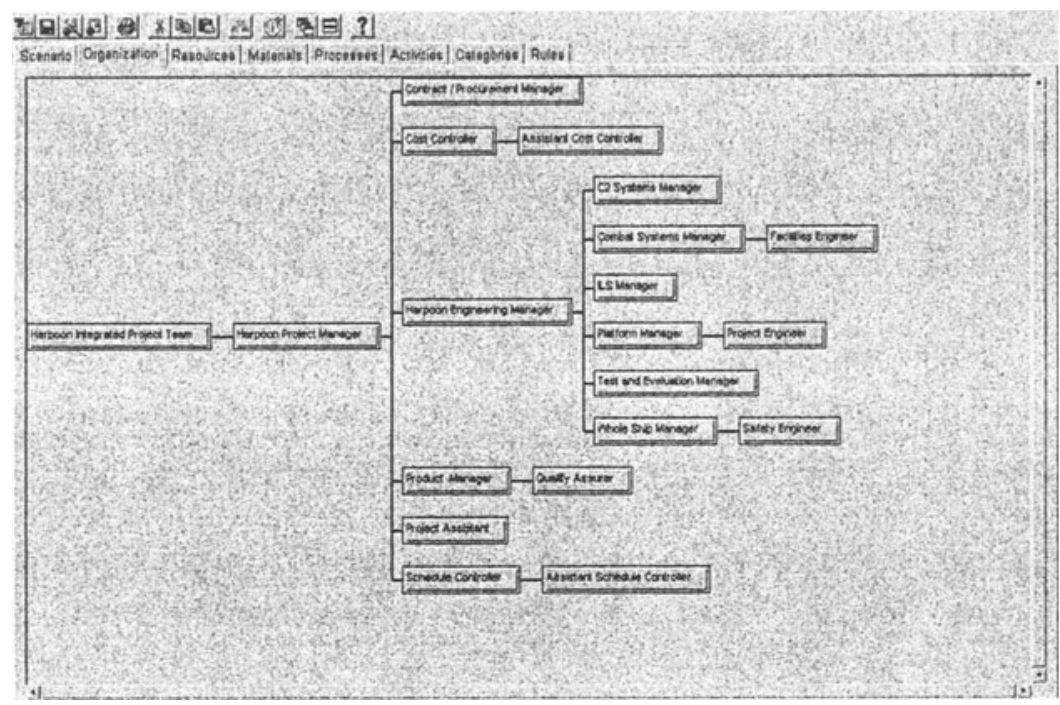

Figure 1 - Organisational chart of Harpoon project

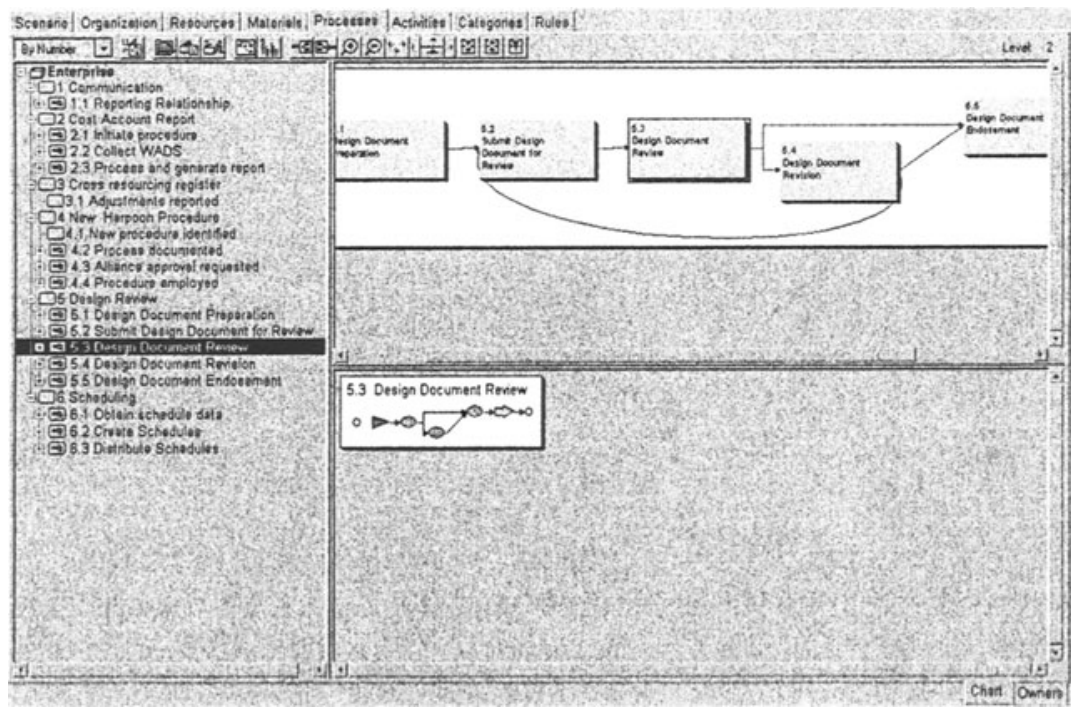

Figure 2 - Process model of "Design Document Review" process 


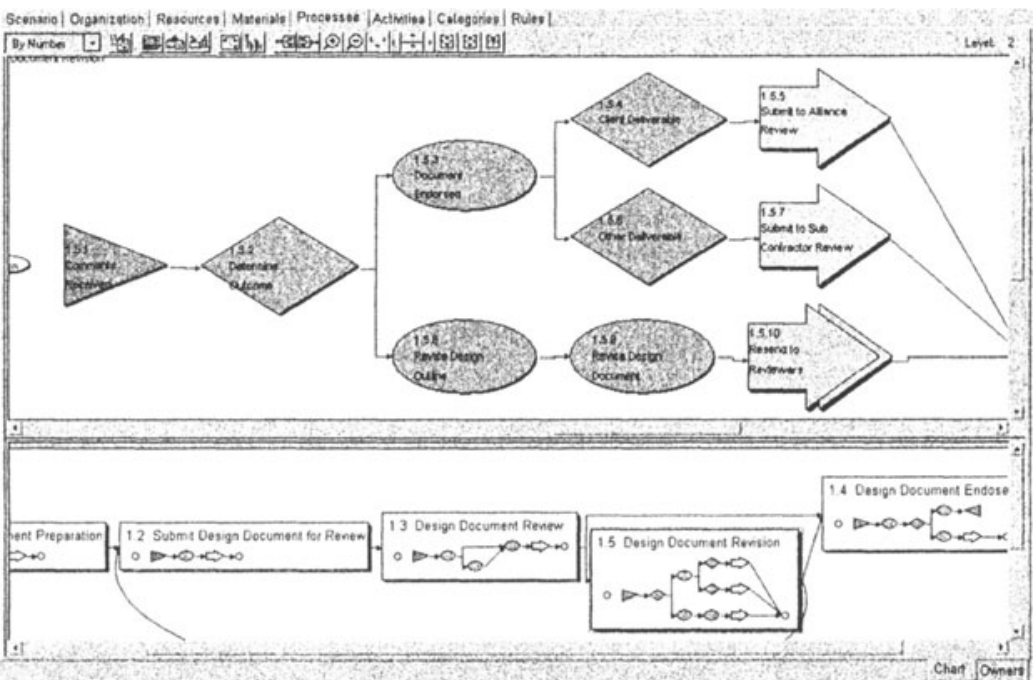

Figure 3 Expanded view of "Design Document Revision"

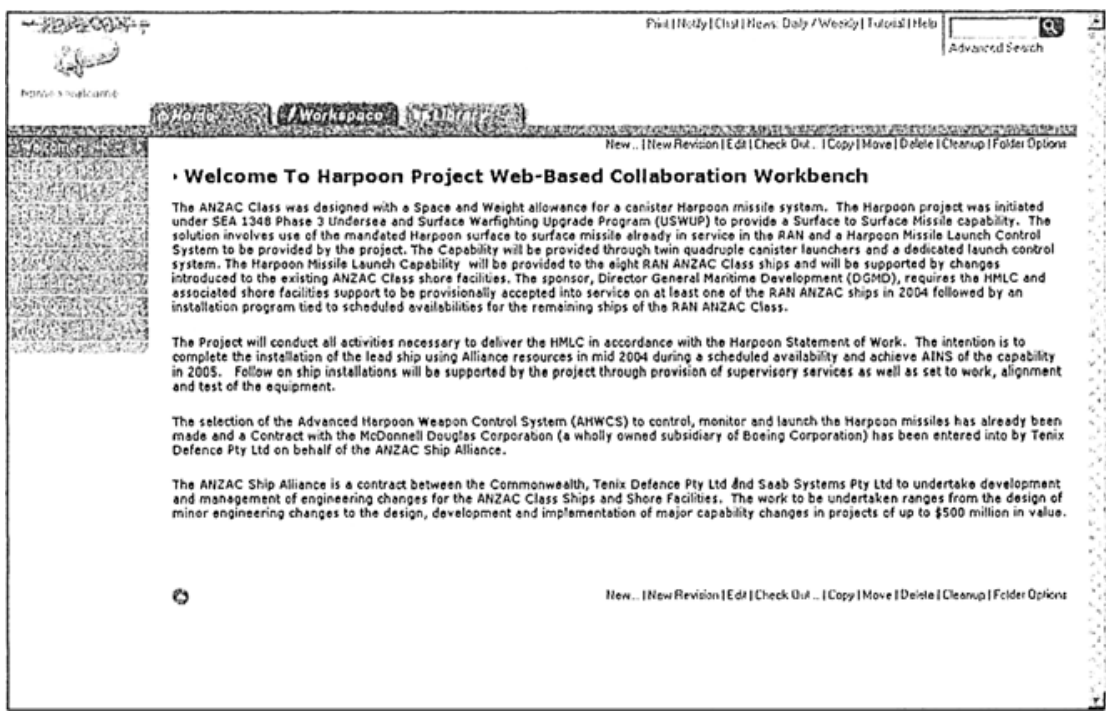

Figure 4 Harpoon project web-based collaboration workbench

\section{SUCCESS FACTORS OF VIRTUAL ENTERPRISES}

The experience of the ANZAC Ship Alliance as a "large" virtual enterprise highlighted a few interesting factors that any virtual enterprise should observe in order to succeed. We assume that most virtual enterprises will be working on projects of significant value and resource commitment; otherwise, it would not be cost effective to form a partnership. Under these circumstances, it is important to 
establish a framework of processes and systems to assist the operation of the virtual enterprise for the reason of extracting efficiency, even at a small percentage of savings.

Firstly, we recommend that project processes should be formalised and the associated QA plans developed for the following processes:

- Collaboration and information sharing

- Document review and endorsement

- Project operation \& management

- Project reporting with project control panel

- Risk tracking and communication

Our observation of the ANZAC Ship Alliance clearly demonstrates the need to deal with these processes at the beginning of the virtual enterprise in this order of importance.

Secondly, we recommend the development of a web-based IT platform for the above processes, to assist project members and to facilitate the integration of other procedures throughout the virtual enterprise. If necessary, different IT platforms should be evaluated against the working criteria for these processes.

Thirdly, an interaction process supporting the information needs of projects should be developed among all the functions of the virtual enterprise. In the case of ANZAC Ship Alliance, the objectives of the centrally supported virtual enterprise processes of the ASAMO should be aligned with the project based missions such as Harpoon. A "Request Tracking System" could successfully facilitate this process. The system receives "request for information" from projects and searches for "who has the answer". If the search is successful, it re-directs the request to a person, otherwise, it prompts the system operator who searches for the answer via other means. When the latter happens, the tacit and informal knowledge base in the virtual enterprise is set to action. Furthermore, the system will collect (or help to accumulate) data from known databases and from people who provide the answer so that a complete picture can be delivered to the requesting project manager. It is also important that the system can periodically keep the requesting project manager upto-date of where and at what status his/her request.

This "Request Tracking System" is the human face of the virtual enterprise that coordinates the effort of individual partners and participating staff to the entire knowledge repository that people bring together in the virtual enterprise.

Finally, a web-based document management system properly structured and indexed should be developed to provide an information repository accessible by all members in the virtual enterprise. This recommendation is commonly found in many other virtual enterprise studies. The system will include:

- Alliance policies, procedures and guidelines

- Commonwealth documents and standards

- Supplier and sub-contractor profiles

- Class related skills and competencies

The web based document management system serves as the data repository for the entire virtual enterprise. It captures the explicit knowledge of partners and outcomes of cooperative interactions among members. It is an information library for all partners and hence represents the "static" aspect of the virtual enterprise. When it is used in conjunction with the "Request Tracking System" described 
above, queries can be handled efficiently by linking the "human face" with loads of hard cold data.

\section{CONCLUSION}

The ANZAC Ship Alliance is a " large" operating virtual enterprise formed by 3 major partners for a definite mission of upgrading the ANZAC class frigates over their life time. This study, which was built on an earlier study of a virtual enterprise concentrating on higher level issues, is focused on the problems of supporting activities in a large project relating to the ANZAC ship. The study found that application of latest ICT is not sufficient to ascertain successful execution of the project. A top down approach has been adopted in the study to describe the information and organisational links in the virtual enterprise. Using software modeling tools and PERA methodology, the need for formalising the "Design Document Review" process was identified and a prototype web-based work flow system was developed to support the project team.

The experience has brought 4 recommendations for other virtual enterprises to consider when commencing their partnership. The recommendations can be further enhanced for the purpose of providing a framework for building a working virtual enterprise if necessary.

\section{Acknowledgement}

This research was funded by the CRC for Intelligent Manufacturing Systems and Technology, the Department of Industry, Tourism and Resources and the Commonwealth Scientific and Industrial Research Organisation, Australia. The authors were also grateful to the kind cooperation of the ANZAC Ship Alliance and project members of Harpoon project without which this study would be impossible.

\section{REFERENCES}

1. Chen D., Vallespir B., Doumeingts G. GRAI integrated methodology and its mapping onto generic enterprise reference architecture and methodology. Computers in Industry, Vol.33, 1997, pp.387394

2. Kosheff B. QuickPlace: Brave, new Workplace. Iris Today Archives, Issue on 1 March, 1999, http://www-10.lotus.com/ldd/products.nsf/products/quickplace

3. Mo J.P.T. Aligning your CM system with your business processes. Intranet Content Management Conference, 20-21 November, 2002, Sydney, Australia

4. Mo J.P.T., Nemes L., Zhou M., Anticev J. Content management system and its alignment to business processes. $7^{\text {th }}$ IFAC Workshop on Intelligent Manufacturing Systems, IMS 2003, Paper 24, Budapest, Hungary, April 6-8, 2003

5. Williams T.J. The Purdue Enterprise Reference Architecture. Computers in Industry, Vol.24, No.2-3, 1994, pp.141-158 